\title{
A High Conversion Gain Envelope Detector with Wide Input Range for Simultaneous Wireless Information and Power Transfer System
}

\author{
Yan Li ${ }^{1,2,3} \mathbb{D}$, Xin Liu ${ }^{1,2, *}$, Xiaosong Wang ${ }^{1,2}$, Qian Su ${ }^{1,2,3}$, Shuaipeng Zhao ${ }^{1,2}$, Zhiqiang Wang $1,2,3$ and Yu Liu ${ }^{1,2, *}$ \\ 1 Research and Development Center of Healthcare Electronics, Institute of Microelectronics of Chinese \\ Academy of Sciences, Beijing 100029, China; liyan2@ime.ac.cn (Y.L.); wangxiaosong@ime.ac.cn (X.W.); \\ suqian@ime.ac.cn (Q.S.); zhaoshuaipeng@ime.ac.cn (S.Z.); wangzhiqiang@ime.ac.cn (Z.W.) \\ 2 Beijing Key Laboratory of RFIC Technology for Next Generation Communications, \\ Institute of Microelectronics of Chinese Academy of Sciences, Beijing 100029, China \\ 3 University of Chinese Academy of Sciences, Beijing 100049, China \\ * Correspondence: liuxin@ime.ac.cn (X.L.); liuyu5@ime.ac.cn (Y.L.)
}

check for updates

Citation: Li, Y.; Liu, X.; Wang, X.; Su, Q.; Zhao, S.; Wang, Z.; Liu, Y. A High Conversion Gain Envelope Detector with Wide Input Range for Simultaneous Wireless Information and Power Transfer System. Electronics 2021, 10, 160. https://doi.org/10.3390/ electronics10020160

Received: 15 December 2020 Accepted: 11 January 2021 Published: 13 January 2021

Publisher's Note: MDPI stays neutral with regard to jurisdictional clai$\mathrm{ms}$ in published maps and institutional affiliations.

Copyright: (C) 2021 by the authors. Licensee MDPI, Basel, Switzerland. This article is an open access article distributed under the terms and conditions of the Creative Commons Attribution (CC BY) license (https:// creativecommons.org/licenses/by/ $4.0 /)$.

\begin{abstract}
Wireless sensors networks (WSN) have been gradually facilitating the pervasive connectivity of wireless sensor nodes. A greater number of wireless sensors have been used in different aspects of our life. However, limited device battery life restricts the applications of large-scale WSN. This paper presents a batteryless envelope detector with radio frequency energy harvesting (RFEH) for wireless sensor nodes, which enables simultaneous wireless information and power transfer (SWIPT). The envelope detector is designed for small modulation index AM signals with large amplitude variations. Therefore, the envelope detector is supposed to have wide input range while achieving a high conversion gain. We proposed an adaptive biasing technique in order to extend the input range of envelope detector. The input differential pair is adaptively biased through a feedback loop to overcome the variation of bias point when the amplitude of input signal changes. The cross coupled rectifier and DC-DC boost converter with maximum power point tracking (MPPT) are presented against power conversion efficiency (PCE) degradation of RF rectifier with the input power varying. The adaptive biased envelope detector is theoretically analyzed by square law MOSFET model. Designed with $0.18 \mu \mathrm{m}$ complementary-metal-oxide-semiconductor (CMOS) standard process, the power consumption of proposed envelope detector is $9 \mu \mathrm{W}$. Simulated with a $915 \mathrm{MHz}$ AM input signal with $2 \mathrm{Mbps}$ data rate and 0.05 modulation index, the proposed envelope detector achieves $20.37 \mathrm{~dB}$ maximum conversion gain when the amplitude of input signal is $0.5 \mathrm{~V}$, and the PCE of energy harvesting circuits achieves $55.2 \%$ when input power is $-12.5 \mathrm{dBm}$.
\end{abstract}

Keywords: envelope detector; RF energy harvesting (RFEH); simultaneous wireless information and power transfer (SWIPT); maximum power point tracking (MPPT)

\section{Introduction}

Mutifunctional sensors have been widely used in our daily life. These tiny sensors, which can wirelessly communicate in short ranges, represent significant roles in various areas, such as the predictive maintenance of structures, smart buildings, and safety control in automotive applications [1]. However, battery replacement is arduous work, especially in a large WSN. In some cases, it is even hard to obtain access to these sensors in person. Energy harvesting is an attractive solution of the energy-constrained sensor nodes in WSN to perpetually capture energy from ambient environment and convert to DC supply. By adopting energy harvesting in WSN, the maintenance cost can be reduced with enhanced flexibility in practical deployment [2]. Several kinds of ambient energy sources have been widely used in energy harvesting systems, such as heat, vibration, light, and radio frequency (RF) energy [3-5]. From above, RF energy is the most applicable energy source 
for WSN applications as compared with others due to the ubiquity of RF signals. RF energy harvestor can convert RF power to DC supply power. If the RF energy source is stable, the DC power will be permanently provided by RF energy harvesting system. RF energy has been already used in many applications, such as electric vehicles and implantable medical devices [6,7]. In order to implement RF energy harvesting and wireless data receiving in wireless sensor nodes, one solution is to use two links that are in different frequency bands to separately harvest RF energy and transfer wireless data. Generally, the RF energy signal is much stronger than the RF data signal. These two frequency bands must have enough separation in order to protect RF data signal from the interference.

Figure 1 shows the configurations of conventional energy harvestor and data receiver systems. It can be seen that RF energy harvestor and data receiver are two relatively independent systems. There are two sets of antennas and impedance matching networks in the systems. In circuits design, the passive elements, such as antennas and inductors, are very bulky. Moreover, two different frequency bands will occupy more bandwidth, which is a precious resource in current society. Therefore, it is desirable to use a single RF signal in order to implement RF energy harvesting and wireless data receiving [8].

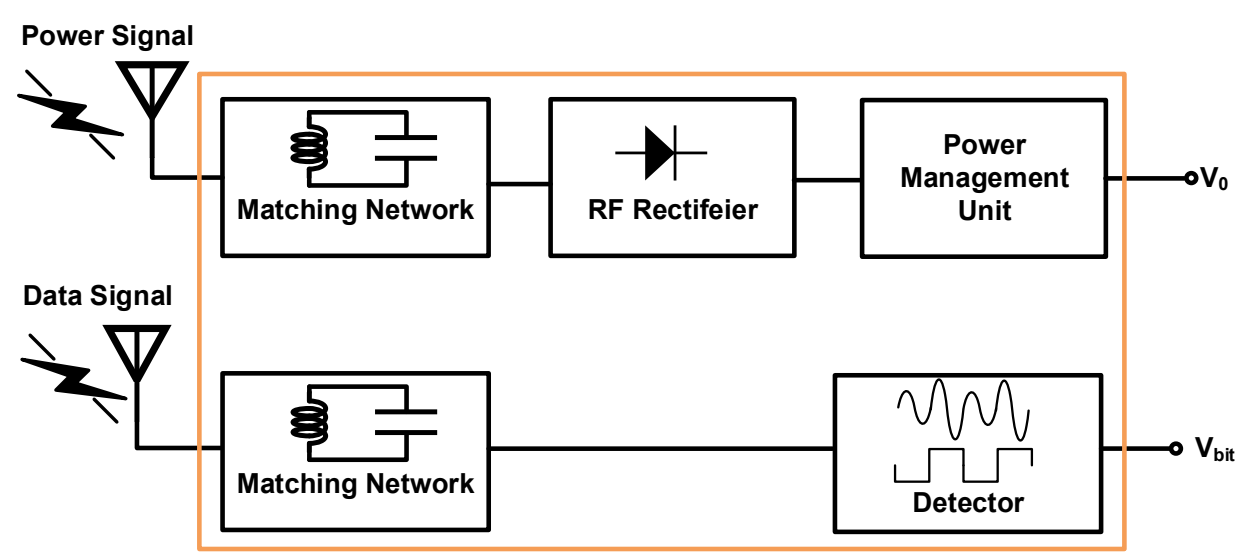

Figure 1. Block diagrams of conventional RF energy harvestor and data receiver system.

Figure 2 presents our proposed RF energy harvestor and wireless data receiver system, the received RF signal is used both for energy harvesting and data transfer. Amplitude modulation (AM) is preferred in these applications, due to its lower power consumption and less circuit complexity in demodulation [9].

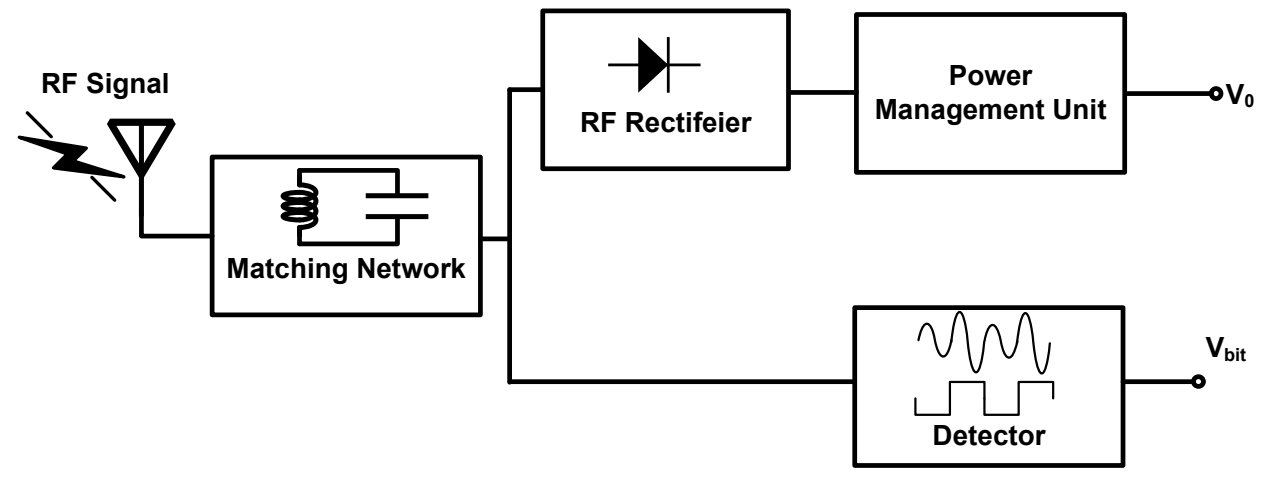

Figure 2. Block diagrams of proposed radio frequency $(\mathrm{RF})$ energy harvestor and data receiver system.

Equation (1) shows the expression of AM signal. Where $A$ is the amplitude of the signal, $\mathrm{m}$ is the modulation index, $X_{B B}(t)$ is the baseband signal, and $\omega_{\mathcal{C}}$ is the carrier frequency.

$$
X_{A M}(t)=A\left[1+m X_{B B}(t)\right] \cos \omega_{c} t
$$


It is clear that the amplitude of AM signal is $A(1+m)$ and $A(1-m)$ when the baseband data is symbol 1 and symbol -1 , respectively. Therefore, the power of AM signal can be expressed as

$$
P_{A M}(t)=\left\{\begin{array}{lll}
P_{0}(1+m)^{2} & (\text { symbol } & 1) \\
P_{0}(1-m)^{2} & (\text { symbol } & -1)
\end{array}\right.
$$

Suppose that the power conversion efficiency (PCE) of the WPT os represented as $X$ and the probabilities of symbols 1 and symbol -1 are equal. Thus, the effective PCE (EPCE) of the RF energy harvesting is as following.

$$
E P C E=X \frac{\frac{1}{2} P_{0}\left[(1+m)^{2}+(1-m)^{2}\right]}{P_{0}(1+m)^{2}}=X \frac{m^{2}+1}{m^{2}+2 m+1}
$$

Equation (3) indicates that increasing $m$ will degrade the EPCE of RF energy harvesting. In addition, the peak-to-average ratio (PAR) of AM signal is directly decided by the $m$, as shown in Equation (4) [10].

$$
P A R=(1+m)^{2}
$$

A big PAR means a large variation of power, which requires regulating processes by battery management circuits and further degrades the PCE of the entire system [11]. Therefore, AM signals with small modulation index is preferred and a sensitive AM demodulator for AM signals with small modulation index is considered to be the prerequisite for realizing the RF energy harvestor with the wireless data receiver system.

Figure 3 shows a typical AM demodulator, which is widely used in radio frequency identification (RFID) [12]. However this topology is less sensitive and it can be hardly used for small modulation index AM signals. The conversion gain of the envelope detector is less than 1 , because the conventional envelope detector is only composed of passive devices. When the modulation index of AM signals is small, the comparator cannot determine the correct results, due to the effect of noise and offset. Moreover, envelope detectors containing active devices, such as MOSFETs, can provide high conversion gain. The circuit that is depicted in Figure 4 is a common implementation of an active envelope detector [13].

However, the amplitude of AM signal may also change due to other factors besides modulation, such as the distance to the RF signal source and obstructions. Thus, the demodulator must have a relatively wide input range. The amplitude variation of input RF signal may change the bias point of the active devices, resulting in saturation and distortion, which limits the input range.

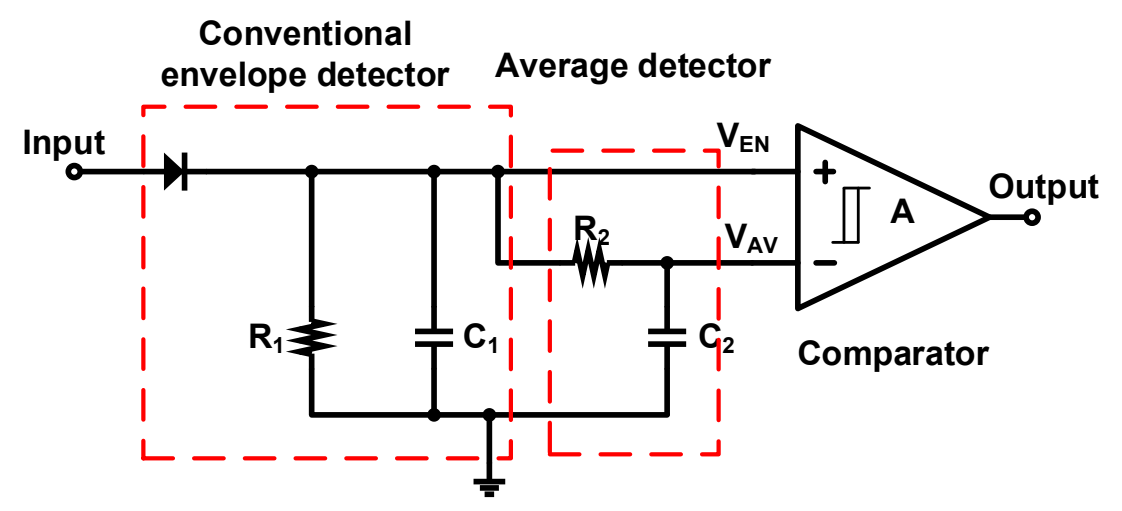

Figure 3. Typical configuration of amplitude modulation (AM) demodulation. 


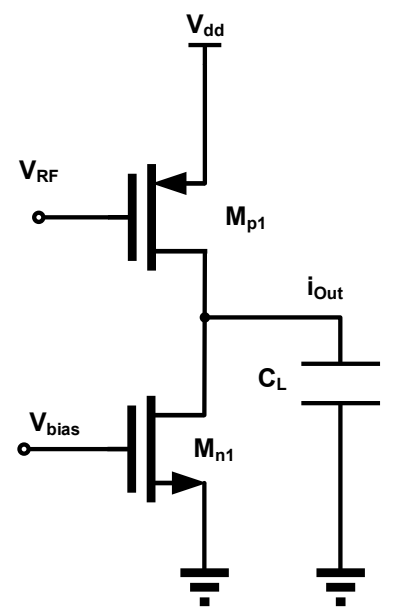

Figure 4. Conventional active envelope detector.

In order to address the problem mentioned above, we proposed a low power envelope detector with an adaptive biasing technique. The large conversion gain is obtained through the amplification of differential pair, and the biasing voltage of input differential pair is generated through the feedback loop that is based on the input signal, so the envelope detector can work in a wide input range. The RF rectifier and DC-DC boost converter with MPPT are also implemented in order to achieve a higher PCE in wide input power range. The rest of the paper is organized, as follows. Section 2 theoretically analyzes the conversion gain of proposed envelope detector and shows the effectiveness of proposed adaptive biasing technique. Section 3 presents the RF rectifier and DC-DC boost converter with MPPT. Section 4 presents the simulation results. Finally, Section 5 concludes the entire work.

\section{Theoretical Analysis of Proposed Envelope Detector}

Figure 5 shows the schematic of proposed envelope detector.

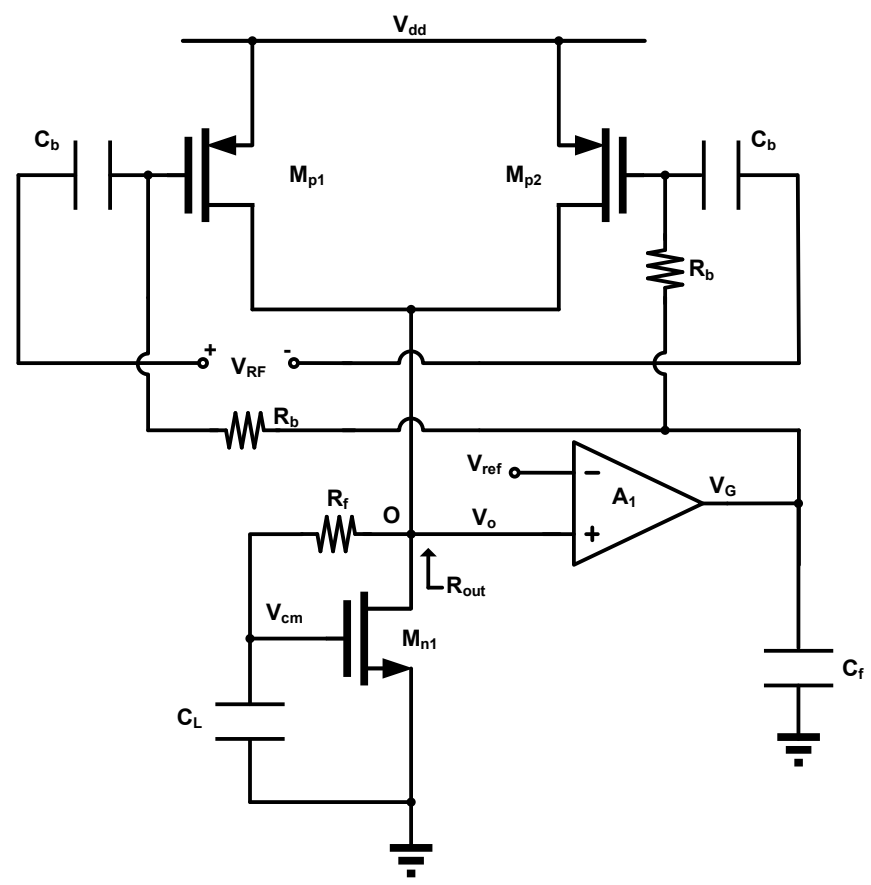

Figure 5. Schematic of proposed envelope detector. 
The proposed envelope detector is composed of a common source PMOS differential pair $M_{p 1}, M_{p 2}$, a NMOS transistor $M_{n 1}$ as a current source, and an error amplifier $A_{1}$. The output signal $V_{o}$ is the baseband signal, which can be further amplified through the baseband amplifier. When the RF signal $X_{A M}(t)$ is applied, while assuming the gate voltage of $M_{p 1}$ is $V_{g 1}$ and expressed as Equation (3). $V_{G}$ is the biased voltage, which is generated by the feedback loop. $v_{g}$ is the amplitude of input signal, $m$ is the modulation index, $X_{B B}(t)$ is the baseband signal, and $\omega_{c}$ is the carrier frequency. It is difficult to analyze this kind of circuit, because, usually, the amplitude of input signal $v_{g}$ is large, the MOSFET transistor works on the strong inversion region and weak inversion region in one frequency period. In this paper, we present a theoretical analysis method by using the square law MOSFET model. We first analyze the envelope detector in an open loop condition, and calculate the conversion gain of the baseband signal.

$$
\begin{gathered}
V_{g 1}(t)=V_{G}+v_{g}\left[1+m X_{B B}(t)\right] \cos \omega_{c} t \\
V_{g 1}(t)=V_{G}+v_{g} \cos \omega_{c} t+v_{g} m X_{B B}(t) \cos \omega_{c} t
\end{gathered}
$$

Because the modulation index of the AM signal $m$ is small, therefore $v_{g} m X_{B B}(t) \cos \omega_{c} t$ can be seen as small signal, and $V_{G}+v_{g} \cos \omega_{c} t$ is the quasi-static operating point of $M_{p 1}$. The output current of $M_{p 1}$ can be expressed as

$$
\begin{aligned}
I_{D 1} & =f\left[V_{G}+v_{g} \cos \omega_{c} t\right]+f^{\prime}\left[V_{G}+v_{g} \cos \omega_{c} t\right] \cdot v_{g} m X_{B B}(t) \cos \omega_{c} t \\
& =I_{Q}\left(\omega_{c} t\right)+g\left(\omega_{c} t\right) \cdot v_{g} m X_{B B}(t) \cos \omega_{c} t
\end{aligned}
$$

The function $f(x)$ is the I-V function of PMOS transistor, and $I_{Q}\left(\omega_{c} t\right)$ and $g\left(\omega_{c} t\right)$ represent the quasi-static current and quasi-static transconductance, respectively. The Fourier expand method is introduced in order to compute the conversion gain of the envelope detector. $I_{n}$ and $g_{n}$ are nth harmonic quasi-static current and nth harmonic quasi-static transconductance, respectively. If the impedance at output node $\mathrm{O}$ is $R_{\text {out }}$, then the conversion gain of baseband signal can be obtained.

$$
\begin{gathered}
I_{Q}\left(\omega_{c} t\right)=\sum_{n=0}^{\infty} I_{n} \cdot \cos \left(n \omega_{c} t\right) \\
g\left(\omega_{c} t\right)=\sum_{n=0}^{\infty} g_{n} \cdot \cos \left(n \omega_{c} t\right) \\
A_{v}=\frac{1}{2} g_{1} R_{\text {out }}
\end{gathered}
$$

MOSFET in a strong inversion region conducts much more current than in a weak inversion region or moderate inversion region. In our design, MOSFET in the strong inversion region contributes the most of the current. Therefore, it is reasonable to use the square law MOSFET model for approximations.

$$
I_{D}=\left\{\begin{array}{l}
I_{Z}\left(\frac{V_{g_{s}}-V_{t h}}{2 n \phi_{t}}\right)^{2} \quad\left|V_{g s}\right| \geq\left|V_{t h}\right| \\
0 \quad\left|V_{g s}\right| \leq\left|V_{t h}\right|
\end{array}\right.
$$

Here, $I_{Z}=2 \mu C_{O X}\left(\frac{W}{L}\right)\left(n \phi_{t}\right)^{2}, \phi_{t}=(k t) / q$ is the thermal voltage, which approximately equals to $26 \mathrm{mV}$ in room temperature, $\mu$ is the carrier mobility, $C_{O X}$ is the gate oxide capacitance per unit area, and $\frac{W}{L}$ is the aspect ratio of the MOSFET. The substrate factor $n$ can be represented as $1+\left[\gamma /\left(2 \sqrt{V_{S B}+2 \phi_{F}}\right)\right]$, where $\phi_{F}$ is the Fermi voltage. In order to 
obtain quasi-static transconductance, we use this PMOS model and take the derivative of $V_{g s}$ and represent $V_{g 1}$ as equation 6. We have

$$
\begin{array}{r}
I_{D}\left(\omega_{c} t\right)= \begin{cases}I_{Z}\left(\frac{V_{G}-V_{S}-V_{t h}+v_{g} \cos \omega_{c} t}{2 n \phi_{t}}\right)^{2} & \left|V_{G}-V_{S}+v_{g} \cos \omega_{c} t\right| \geq\left|V_{t h}\right| \\
0 & \left|V_{G}-V_{S}+v_{g} \cos \omega_{c} t\right|<\left|V_{t h}\right|\end{cases} \\
g\left(\omega_{c} t\right)= \begin{cases}I_{Z} \frac{V_{G}-V_{S}-V_{t h}+v_{g} \cos \omega_{c} t}{2\left(n \phi_{t}\right)^{2}} & \left|V_{G}-V_{S}+v_{g} \cos \omega_{c} t\right| \geq\left|V_{t h}\right| \\
0 & \left|V_{G}-V_{S}+v_{g} \cos \omega_{c} t\right|<\left|V_{t h}\right|\end{cases}
\end{array}
$$

Here, we define the conduction angle is $\Phi=\arccos \left(\frac{V_{G}-V_{S}-V_{t h}}{v_{g}}\right)$. Accordingly, Equations (12) and (13) can be rewritten as

$$
\begin{aligned}
I_{D}\left(\omega_{c} t\right) & = \begin{cases}I_{Z}\left(\frac{v_{g} \cos \Phi+v_{g} \cos \omega_{c} t}{2 n \phi_{t}}\right)^{2} & \left|\omega_{c} t\right| \leq \pi-\Phi \\
0 & \left|\omega_{c} t\right|>\pi-\Phi\end{cases} \\
g\left(\omega_{c} t\right) & = \begin{cases}I_{Z} \frac{v_{g} \cos \Phi+v_{g} \cos \omega_{c} t}{2\left(n \phi_{t}\right)^{2}} & \left|\omega_{c} t\right| \leq \pi-\Phi \\
0 & \left|\omega_{c} t\right|>\pi-\Phi\end{cases}
\end{aligned}
$$

Hence, the average current consumption $I_{0}$ and the first harmonic transconductance $g_{1}$ can be calculated, as follows.

$$
\begin{aligned}
& I_{0}=\frac{2}{\pi} \int_{-\pi+\Phi}^{\pi-\Phi} I_{D}\left(\omega_{c} t\right) d\left(\omega_{c} t\right) \\
&=I_{Z}\left(\frac{v_{g} \cos \Phi+v_{g}}{2 n \phi_{t}}\right)^{2} \cdot \frac{\pi-\Phi+0.75 \sin 2 \Phi+0.5(\pi-\Phi) \cos 2 \Phi}{\pi(1+\cos \Phi)^{2}} \\
& g_{1}=\frac{1}{\pi} \int_{-\pi+\Phi}^{\pi-\Phi} g\left(\omega_{c} t\right) \cos \left(\omega_{c} t\right) d\left(\omega_{c} t\right) \\
&=I_{Z} \frac{v_{g} \cos \Phi+v_{g}}{2\left(n \phi_{t}\right)^{2}} \cdot \frac{\pi-\Phi+\sin \Phi \cos \Phi}{\pi(1+\cos \Phi)}
\end{aligned}
$$

Figures 6 and 7 show the $I_{0}$ and $g_{1}$ characteristics with $\mathrm{W} / \mathrm{L}=1 \mu \mathrm{m} / 0.5 \mu \mathrm{m}$ aspect ratios fabricated in the $0.18 \mu \mathrm{m}$ process based on our calculations. The calculations were done while using Equations (16) and (17), with the condition of $I_{Z}=180 \mathrm{nA}, V_{t h}=-450 \mathrm{mV}$, substrate factor $n=1.3$, and $\phi_{t}=26 \mathrm{mV}$. The source terminal of transistor is biased at $1.8 \mathrm{~V}$ and the source terminal of transistor is grounded. The $I_{0}$ and $g_{1}$ characteristics indicate that it is difficult to achieve wide input range and high conversion gain under low power consumption at the same time. For example, if we want to have a relatively large conversion gain when $v_{g}$ is small, then the biased voltage $V_{G}$ must be low. However, for the low biased voltage $V_{G}$, as $v_{g}$ becomes larger, the average current $I_{0}$ increases dramatically, which increases the power consumption. Therefore, it is not power efficient to set the biased voltage $V_{G}$ at a fixed value.

In this paper, we propose the adaptive biasing technique, which can generate low bias voltage $V_{G}$ when $v_{g}$ is small to obtain a higher conversion gain and high bias voltage $V_{G}$ when $v_{g}$ is large for low power consideration. It is implemented through the constant biasing current. Figures 8 and 9 show the calculation results of $g_{1}$ and $V_{G}$ for $I_{0}=1 \mu \mathrm{A}, 2 \mu \mathrm{A}$, $4 \mu \mathrm{A}$, respectively. It can be shown that, when the MOSFET has constant biasing current, the relatively constant conversion gain can be obtained with low power consumption by properly setting $V_{G}$, according to $v_{g}$. As $I_{0}$ increases, $g_{1}$ will increase accordingly. However, higher $I_{0}$ requires higher $v_{g}$, which limits the input range. 


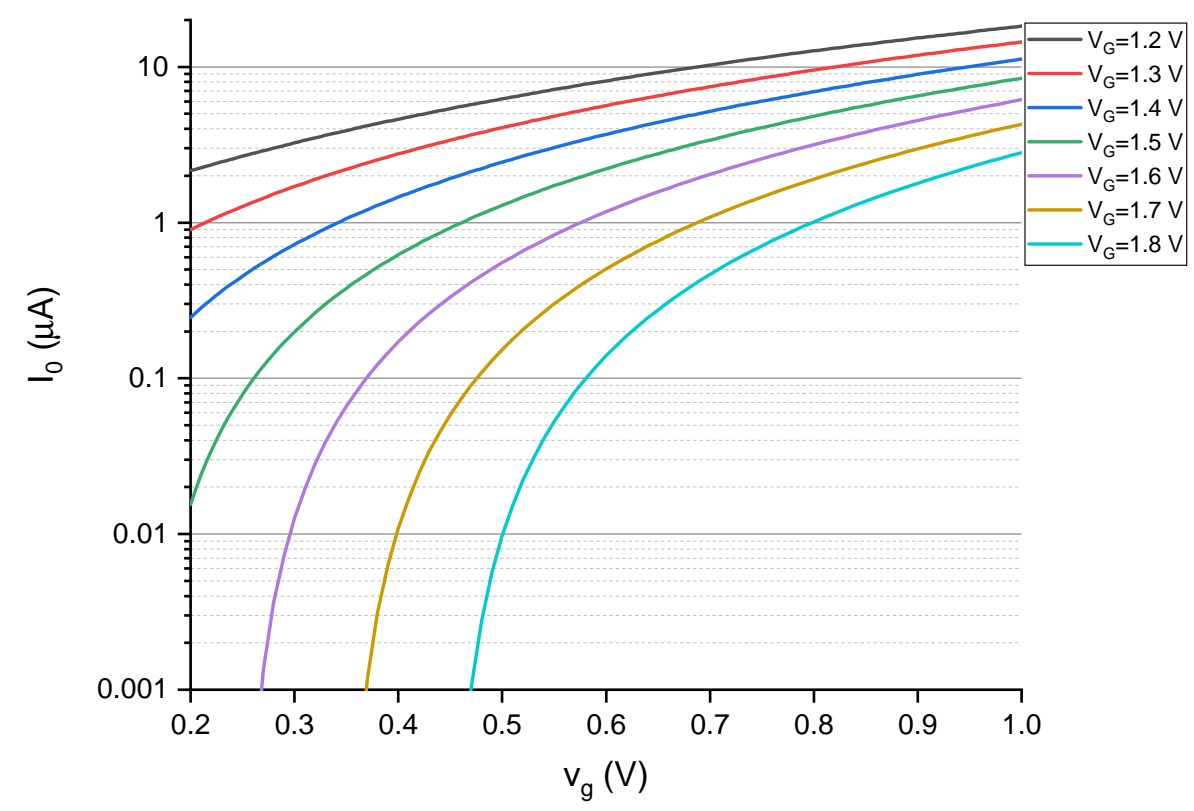

Figure 6. Calculation results of $I_{0}$.

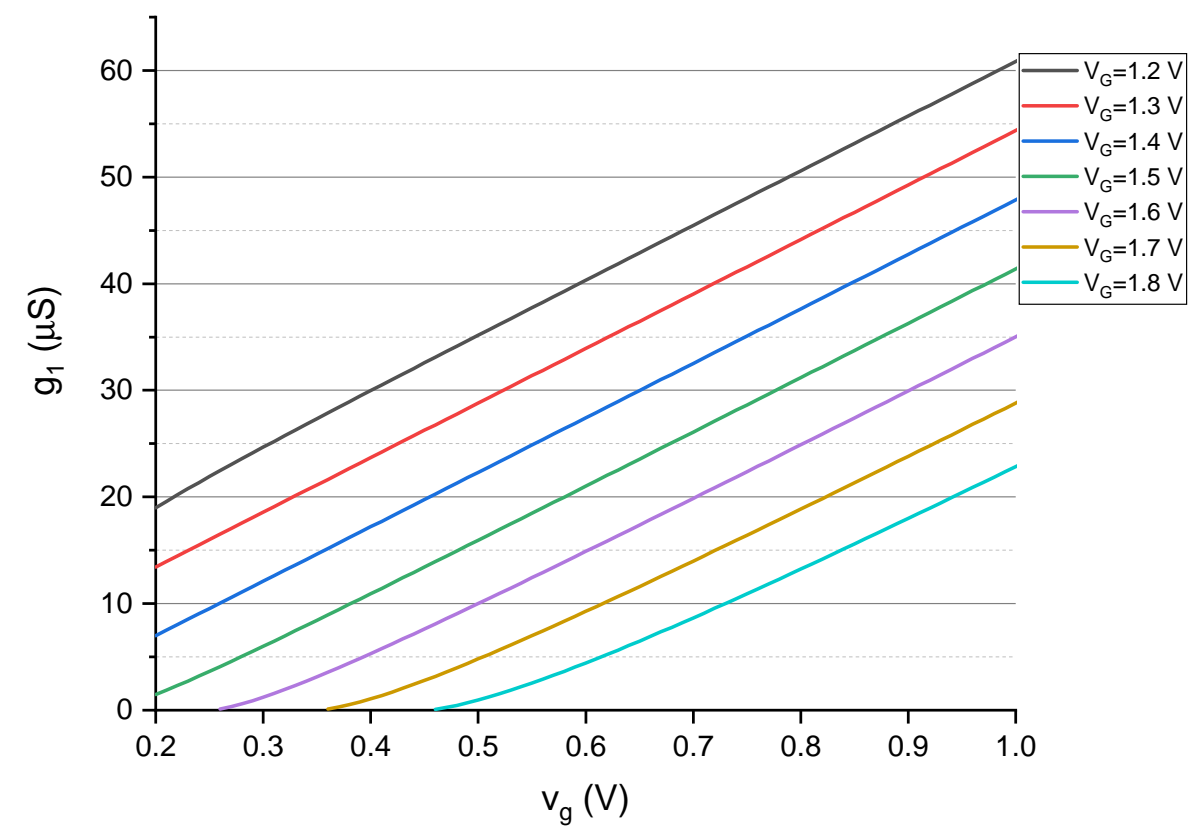

Figure 7. Calculation results of $g_{1}$.

The proposed adaptive biasing technique is implemented through a negative feedback loop. The cut-off frequency of low pass filter $R_{f} C_{L}$ is much lower than the bandwidth of baseband signal, so the gate of transistor $M_{n 1}$ can be seen as AC ground. Therefore, the gate voltage of $M_{n 1}$ approximately equals to $V_{r e f}$ through the feedback loop. Thus, the average current of NMOS transistor $I_{n}$ is as follows.

$$
I_{n}=\frac{1}{2} \mu_{n} C_{o x}\left(\frac{W}{L}\right)_{n 1}\left(V_{r e f}-V_{t h n}\right)^{2}
$$

The adaptive biased voltage $V_{G}$ is generated by error amplifier. For example, as the amplitude of input signal $v_{g}$ increases, the average current of PMOS differential pair is increased. Because $I_{n}$ is fixed, the voltage $V_{o}$ will increase. Therefore, the output voltage of error amplifier will increase in order to generate a higher $V_{G}$, which will decrease the average current of PMOS differential pair. The bias voltage is supposed to only react 
with the average amplitude of input signal in order to generate a stable biased voltage $V_{G}$. Therefore, the bandwidth of the feedback loop need to be lower than the bandwidth of baseband signal. The transfer function of the feedback loop can be approximately expressed, as follows.

$$
H(s)=\frac{2 A_{V 1} g_{m p 1,2} / g_{m n 1}}{\left[1+s R_{O 1}\left(C_{f}+2 C_{b}\right)\right]\left(1+s C_{L} / g_{m n 1}\right)}
$$

where $A_{V 1}$ and $R_{O 1}$ are voltage gain and output impedance of the error amplifier $A_{1}$, respectively. In addition, the low bandwidth of the feedback loop results in the low transient response requirements for error amplifier, which can be easily implemented in low power condition. In our design, a folded cascode topology is adopted for error amplifier, which achieves $50 \mathrm{~dB}$ DC voltage gain with $100 \mathrm{KHz}-3 \mathrm{~dB}$ bandwidth under 1 $\mu \mathrm{A}$ current consumption. Table 1 lists the device parameters that are used in the envelope detector. The average current of proposed envelope detector is $5 \mu \mathrm{A}$, and the supply voltage is $1.8 \mathrm{~V} .1 \mathrm{M} \Omega$ is chosen for $R_{f}$ in order to obtain enough conversion gain.

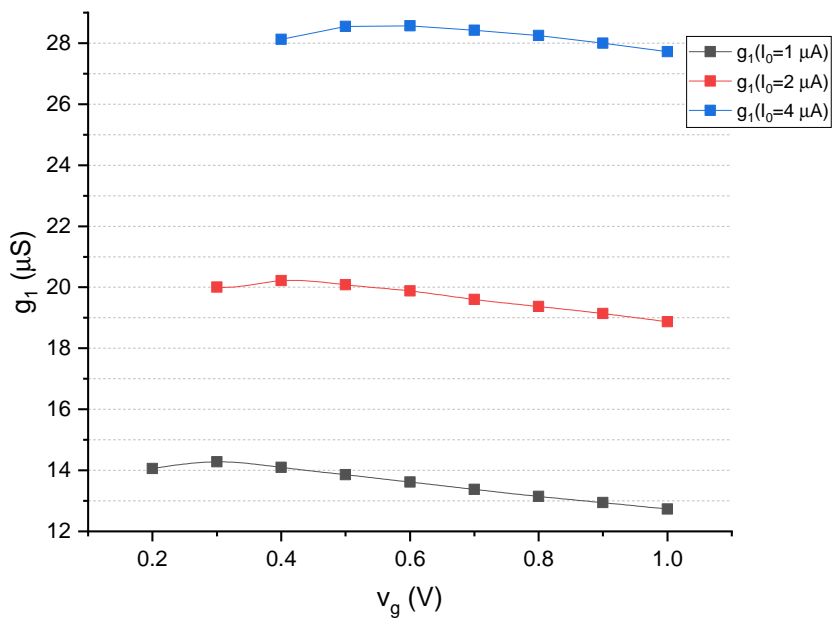

Figure 8. The calculation results of $g_{1}$ for constant $I_{0}$.

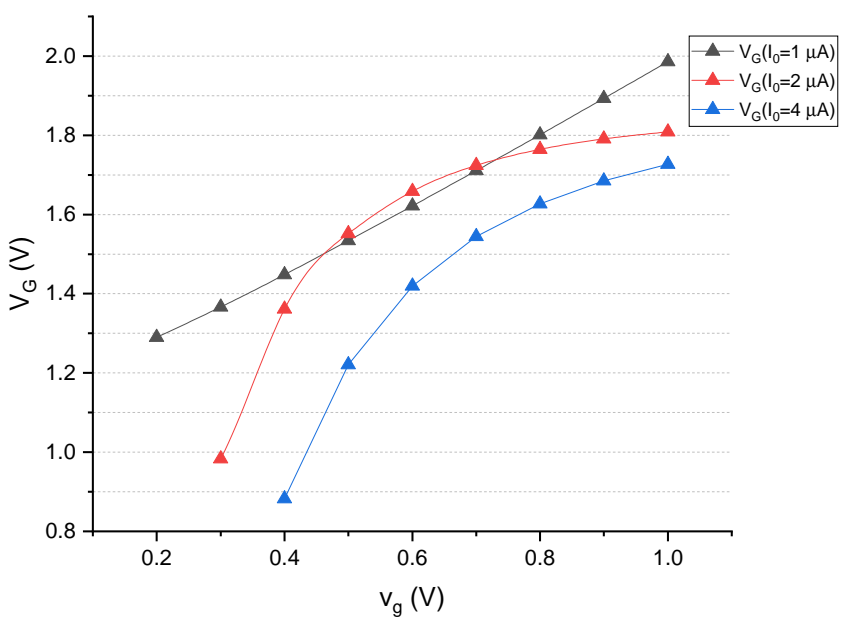

Figure 9. Calculation results of $V_{G}$ for constant $I_{0}$. 
Table 1. Device dmension of envelope detector.

\begin{tabular}{cc}
\hline Device & Size \\
\hline$M_{p 1,2}$ & $1 \mu / 0.5 \mu$ \\
$M_{n 1}$ & $0.5 \mu / 1 \mu$ \\
$R_{b}$ & $200 \mathrm{k} \Omega$ \\
$R_{f}$ & $1 \mathrm{M} \Omega$ \\
$C_{b}$ & $500 \mathrm{fF}$ \\
$C_{L}$ & $5 \mathrm{pF}$ \\
$C_{f}$ & $5 \mathrm{pF}$ \\
\hline
\end{tabular}

\section{RF Energy Harvesting Circuits}

Figure 10 shows the schematic of the proposed RF energy harvesting circuits.

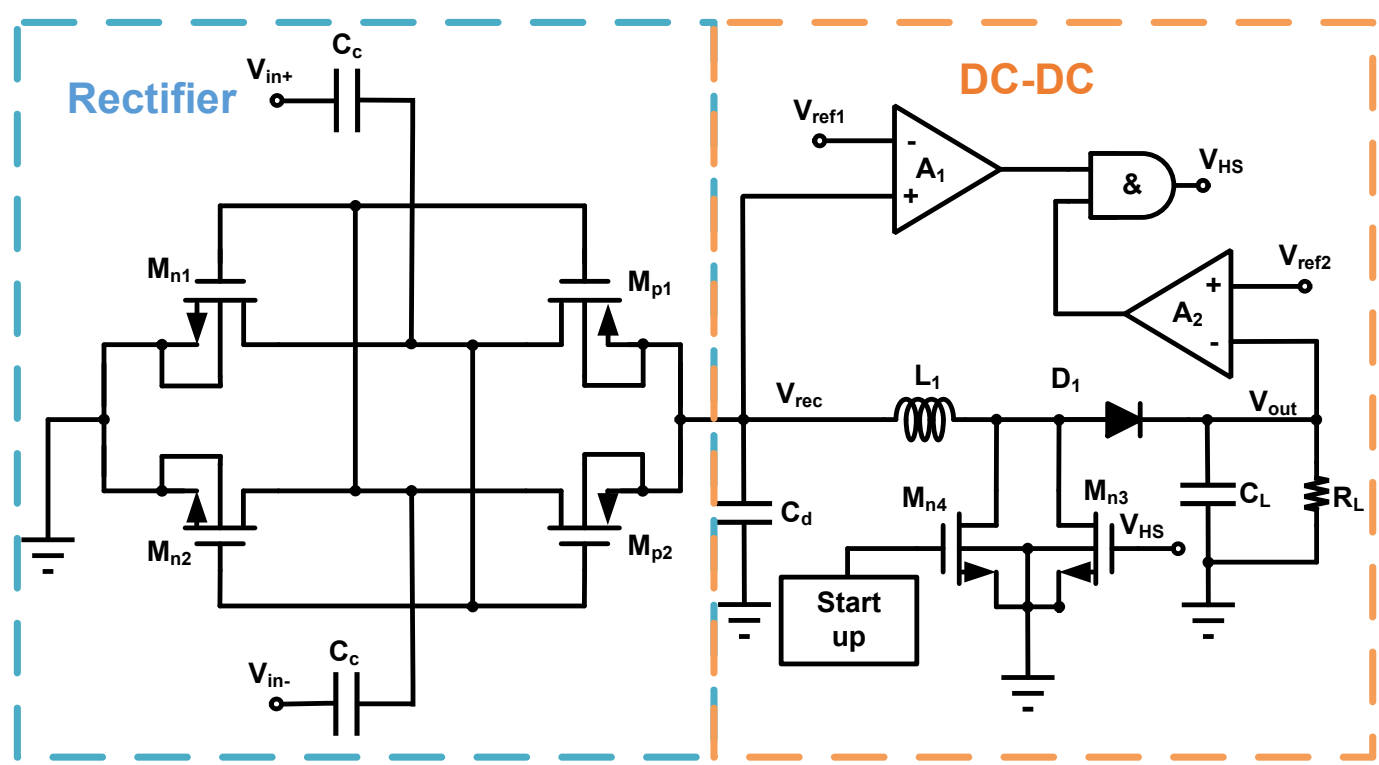

Figure 10. RF rectifier and DC-DC boost converter with maximum power point tracking (MPPT).

It is composed of a cross couple rectifier and a DC-DC boost converter. When compared to diode connection CMOS rectifiers, cross couple rectifiers can achieve much higher PCE. However, the PCE of cross couple rectifiers is highly related to the input power and load impedance. For different input power, the optimum load impedance of rectifier to obtain the highest PCE is different. As the input power changes, the PCE will quickly degrade. Figure 11 shows the simulated PCE of cross coupled rectifier with different load impedances. The rectifier has a NMOS transistor size of $100 \mu \mathrm{m} / 0.18 \mu \mathrm{m}$ and PMOS transistor size of $160 \mu \mathrm{m} / 0.18 \mu \mathrm{m}$. It can be shown that, if we keep the load impedance of rectifier unchanged, the highest PCE can only be obtained at a specific input power. The optimal load impedance changes from $10 \mathrm{~K} \Omega$ to $1 \mathrm{~K} \Omega$ when the input power changes from $-17.5 \mathrm{dBm}$ to $-2.5 \mathrm{dBm}$.

In order to improve the PCE with varying input power, we designed a DC-DC boost converter operating in discontinuous conduction mode (DCM) with maximum power point tracking (MPPT). Figure 12 shows the output voltage of cross coupled rectifier when input power varying. It can be seen that, for each input power, there are optimal load impedance and corresponding optimal output voltage $V_{\text {rec,opt }}$. Because the input power varies from $-17.5 \mathrm{dBm}$ to $-2.5 \mathrm{dBm}$, the $V_{\text {rec,opt }}$ changes slightly from $0.46 \mathrm{~V}$ to $0.53 \mathrm{~V}$.

Therefore, we implemented MPPT by properly setting the output voltage of cross coupled rectifier $V_{\text {rec }}$ close to $V_{\text {rec,opt }}$. Through the negative feedback loop, $V_{\text {rec }}$ is approximately equals to the reference voltages $V_{\text {ref } 1}$. The reference voltages $V_{\text {ref } 1}$ is set to $0.5 \mathrm{~V}$, corresponding to the input power range from $-17.5 \mathrm{dBm}$ to $-2.5 \mathrm{dBm}$. We use off-chip 
Schottky diode $D_{1}$ to reduce voltage drop. In our design, the Schottky diode model is LSM115J, which has only $100 \mathrm{mV}$ forward voltage drop at $400 \mathrm{~mA}$ forward current. The capacitor $C_{d}$ is charged by the rectifier, and the reference voltage $V_{r e f 2}$ is clamping voltage, which is $1.8 \mathrm{~V}$ for over voltage protection in our design.

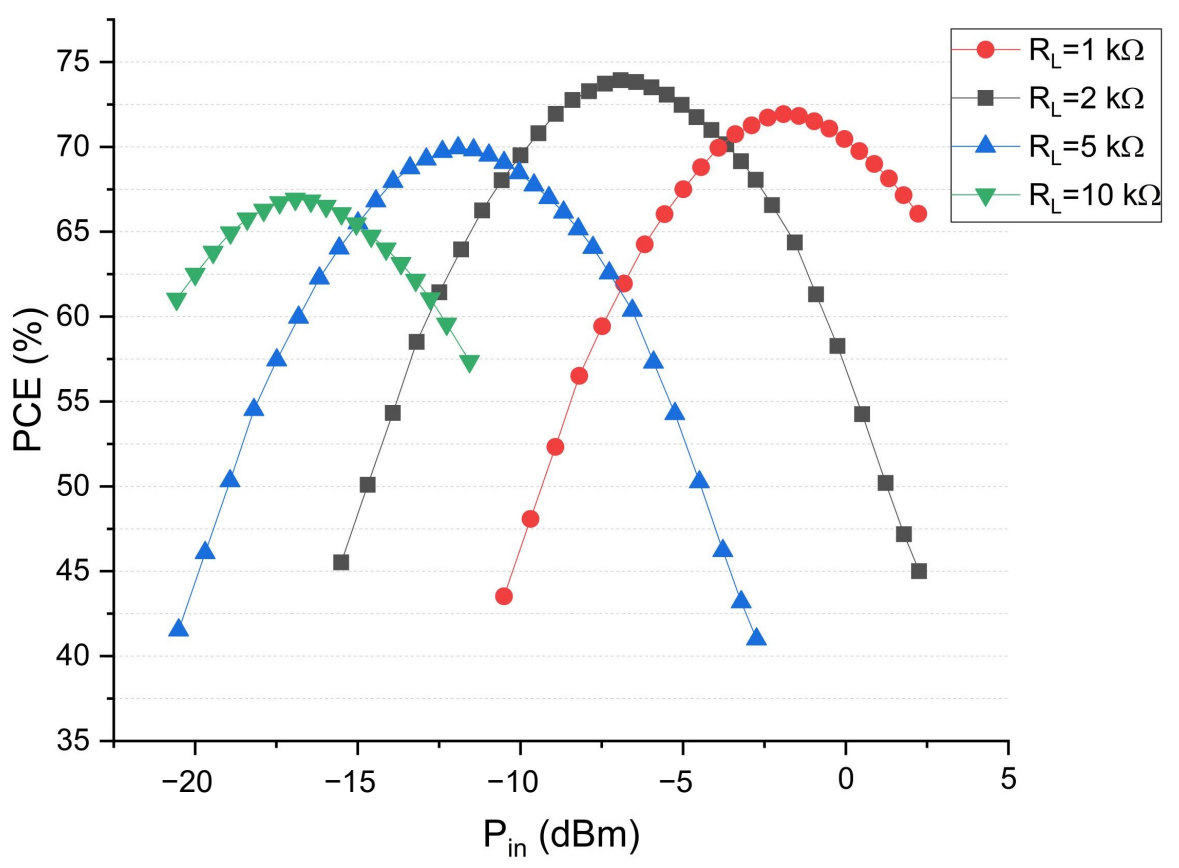

Figure 11. Power conversion efficiency (PCE) of cross coupled rectifier with different load impedances.

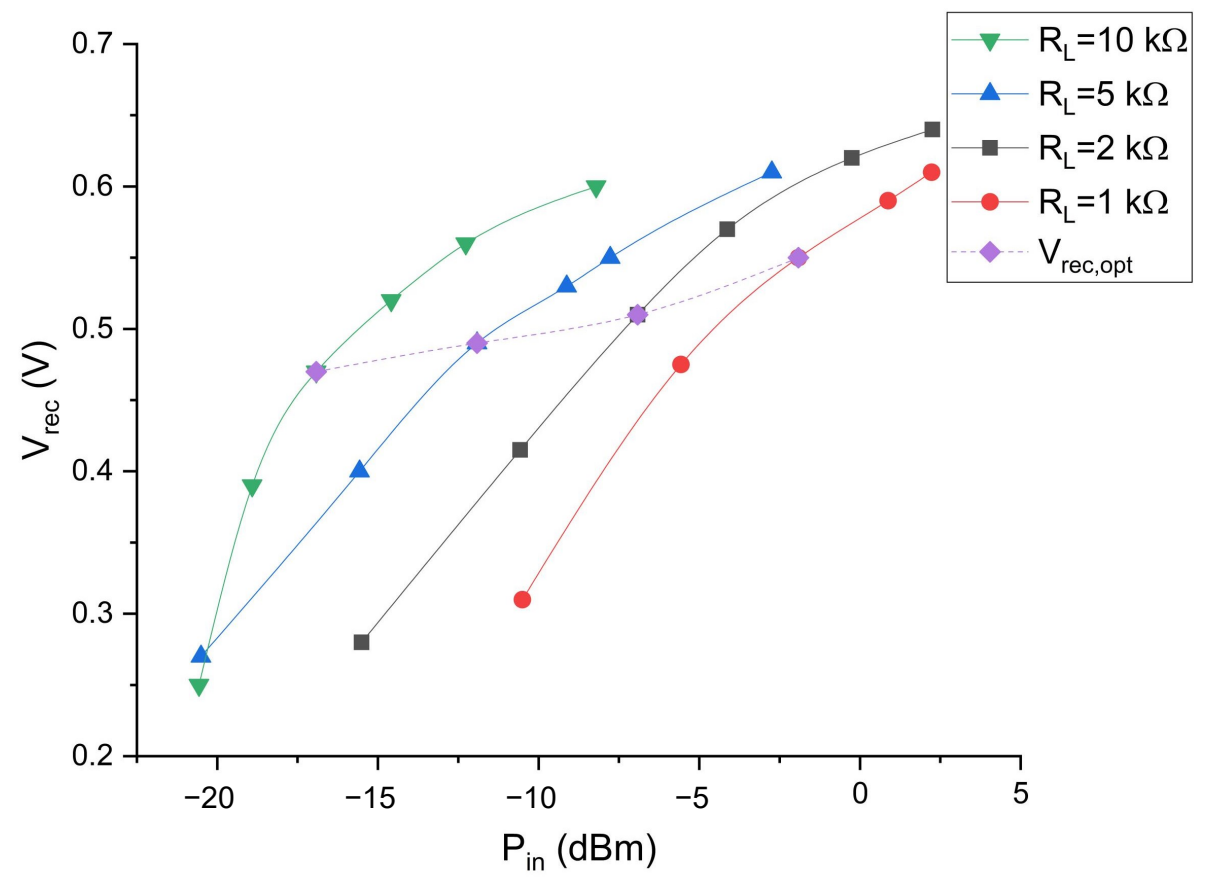

Figure 12. Output voltage of cross coupled rectifier with different load impedances.

The start up circuit is designed in order to achieve cold-start. It is composed of a ring oscillator, which can generate a $50 \%$ duty cycle square wave under $0.48 \mathrm{~V}$ voltage supply. The NMOS transistor $M_{n 4}$ is driven by start up circuit and boost up $V_{\text {out }}$ to $1 \mathrm{~V}$. Once $V_{\text {out }}$ is beyond $1 \mathrm{~V}$, the start up circuit is disabled, and the DC-DC boost converter operates in DCM. 
Figure 13 shows the equivalent circuits of DC-DC boost converter in DCM and its current and voltage waveforms. Figure 13a-c illustrate the operation principle of DC-DC boost converter working in DCM. If the input power increases, the switching MOSFET $M_{n 3}$ will be more frequently conducted, as shown in Figure 13d. Therefore, $I_{L A V}$, the average current of $I_{L}$, increases. The input impedance of DC-DC boost converter is calculated as $V_{d c} / I_{L A V}$, so the input impedance will decrease. The load of cross coupled rectifier is the input impedance of DC-DC boost converter. Accordingly, the load impedance of cross coupled rectifier will decrease when the input power becomes larger. By properly setting $V_{r e f 1}$, the input impedance of the DC-DC boost converter can be approximately equal to the optimum load impedance of rectifier with input power varying. The PCE of cross coupled rectifier can be increased, according to our previous analysis. Table 2 shows the summary information of proposed RF rectifier and DC-DC boost converter.
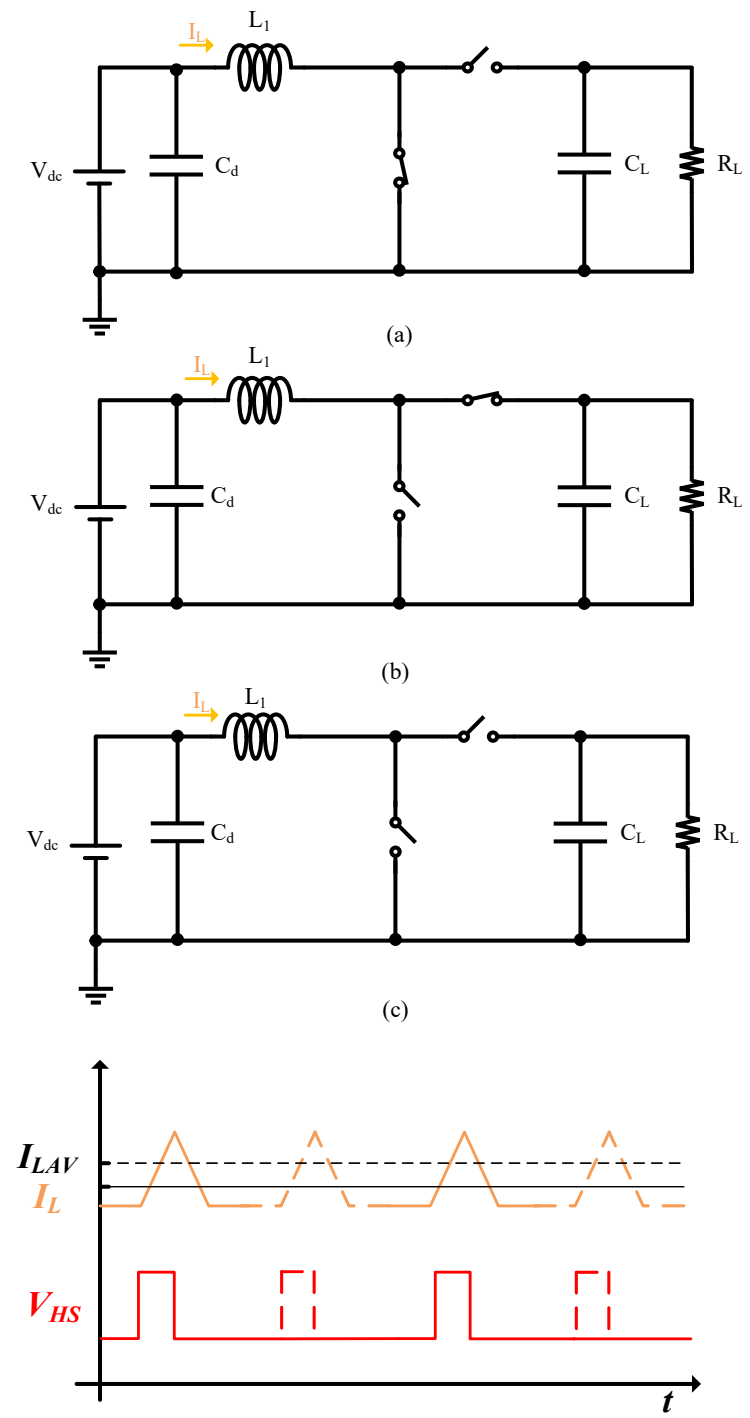

(d)

Figure 13. Equivalent circuits of DC-DC boost converter in discontinuous conduction mode (DCM) and its current and voltage waveforms. (a) Equivalent circuit when the switch is on and the diode is off. (b) Equivalent circuit when the switch is off and the diode is on. (c) Equivalent circuit when both the switch and the diode are off. (d) Current and voltage waveforms of proposed DC-DC boost converter. 
Table 2. The information of RF rectifier and DC-DC boost converter.

\begin{tabular}{cc}
\hline Device & Size/Model \\
\hline$M_{p 3,4}$ & $160 \mu / 0.18 \mu$ \\
$M_{n 4,5,6} \mu 0 \mu / 0.18 \mu$ \\
$M_{n 3}$ & $100 / 0.18 \mu$ \\
$D_{1}$ & $\mathrm{LSM} 115 \mathrm{~J}$ \\
$C_{d}$ & $470 \mathrm{nF}$ \\
$L_{1}$ & $1 \mathrm{mH}$ \\
$V_{r e f 1}$ & $500 \mathrm{mV}$ \\
$V_{r e f 2}$ & $1.8 \mathrm{~V}$ \\
\hline
\end{tabular}

\section{Post-Layout Simulation Results and Discussion}

Our proposed batteryless envelope detector with RF energy harvesting circuits was designed with $0.18 \mu \mathrm{m}$ CMOS standard process. Figure 14 shows the layout of complete system, which has $200 \mu \mathrm{m} \times 300 \mu \mathrm{m}$ active area. Post-layout simulations are performed with $2 \mathrm{Mbps}$ AM modulated signal through Spectre. The RF input signal has $915 \mathrm{MHz}$ carrier frequency with 0.05 modulation index.

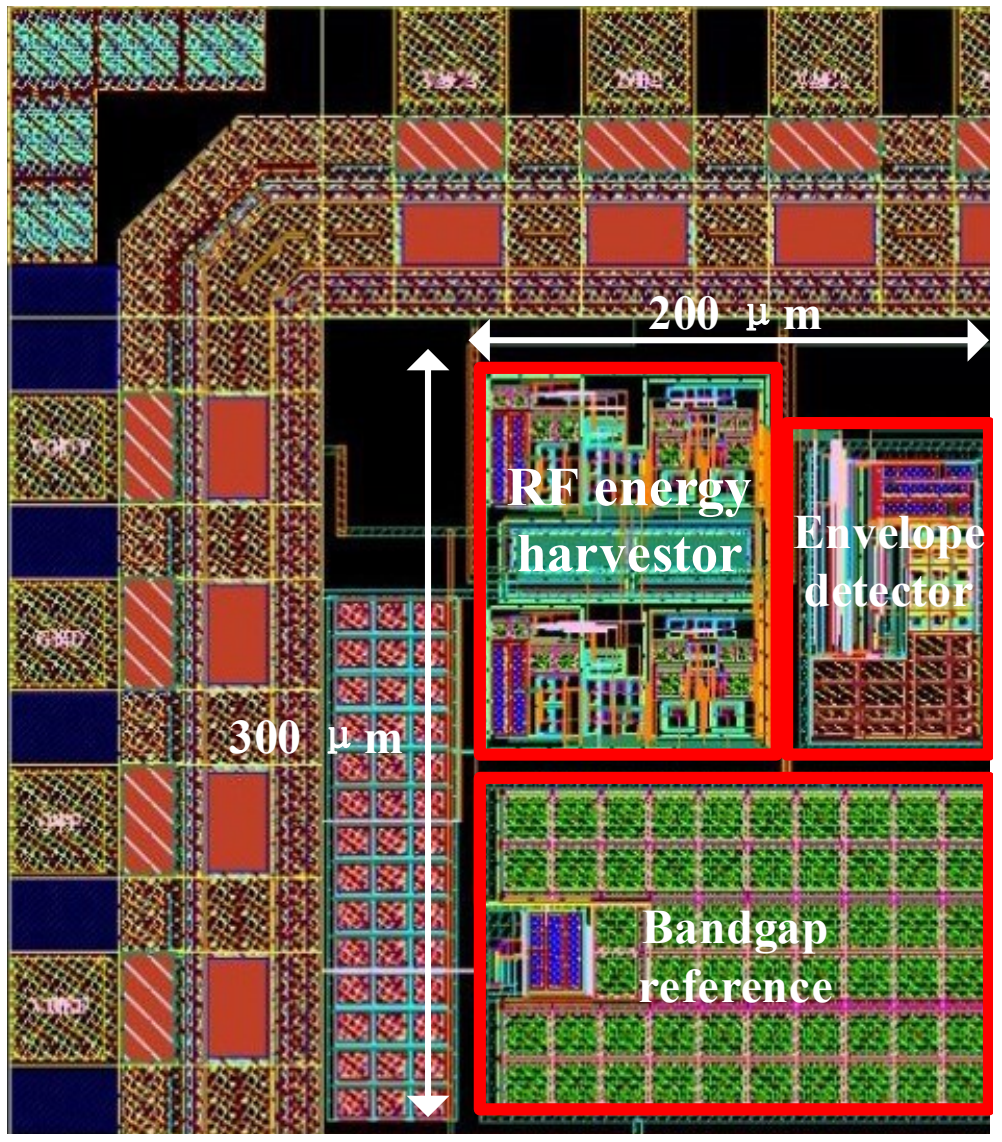

Figure 14. Layout of proposed batteryless envelope detector with RF energy harvesting circuits.

Figure 15 shows the simulation results of envelope detector under $1.8 \mathrm{~V}$ supply voltage. When the amplitude of input signal increases from $0.25 \mathrm{~V}$ to $1 \mathrm{~V}$, the bias voltage $V_{G}$ changes from $0.9 \mathrm{~V}$ to $1.7 \mathrm{~V}$. Thanks to the adaptive biased voltage, the average current $I_{0}$ is almost constant, changing only from $1.96 \mu \mathrm{A}$ to $2.08 \mu \mathrm{A}$. The variation of average current $I_{0}$ is approximately $5 \%$.

Figure 16 shows the conversion gain as a function of the amplitude of the input signal. It achieves $20.23 \mathrm{~dB}$ conversion gain at $v_{g}=0.5 \mathrm{~V}$. The conversion gain is higher than $14 \mathrm{~dB}$ 
in the entire input range due to the adaptive biasing technique. Different from our previous theoretical analysis, the simulation results show that the conversion gain decreases when the amplitude of the input signal becomes larger. This is because, when the input signal becomes larger, the output voltage saturates due to the swing limitation.

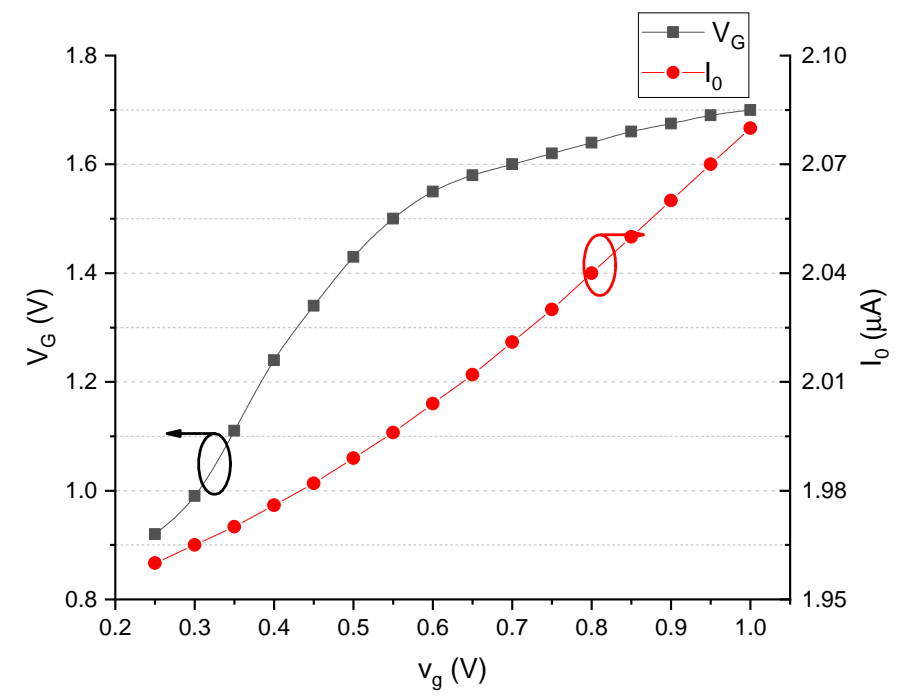

Figure 15. The simulation results of $I_{0}$ and $V_{G}$ with $v_{g}$ varying.

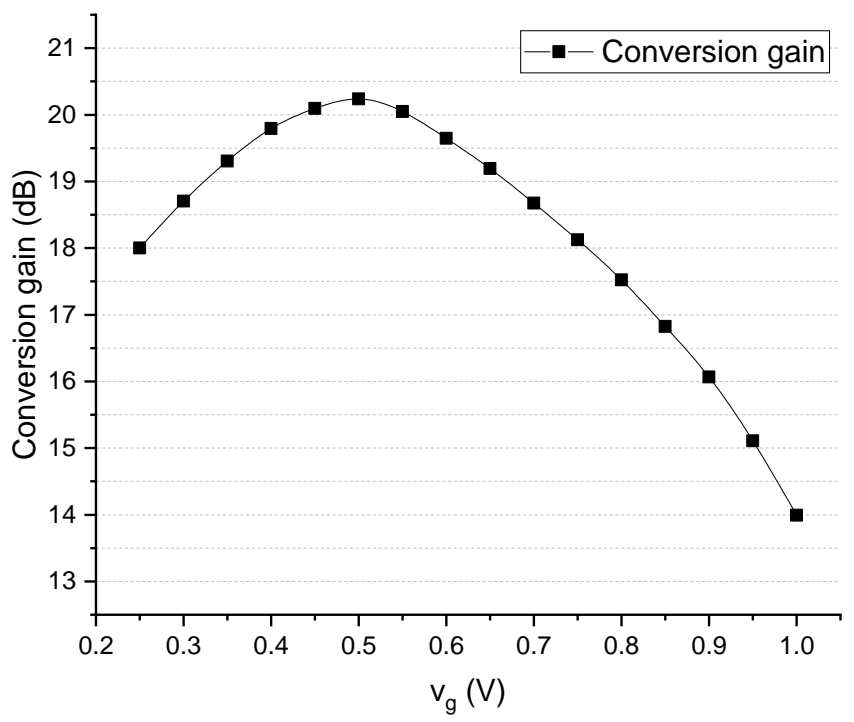

Figure 16. Simulation results of conversion gain $A_{v}$.

Figure 17 shows the simulated timing waveforms of proposed envelope detector. $V_{i n+}$ and $V_{i n-}$ are the differential input signals, which have a $915 \mathrm{MHz}$ carrier frequency with $2 \mathrm{Mbps}$ AM modulated signal, 0.05 modulation index, and $1 \mathrm{~V}$ amplitude. $V_{G}$ is the adaptive biasing voltage of the proposed envelope detector and $V_{O}$ is the envelope detector output. The amplitude of $V_{O}$ increases as $V_{G}$ settling to $1.7 \mathrm{~V}$, which indicates the effectiveness of the proposed adaptive biasing technique. 


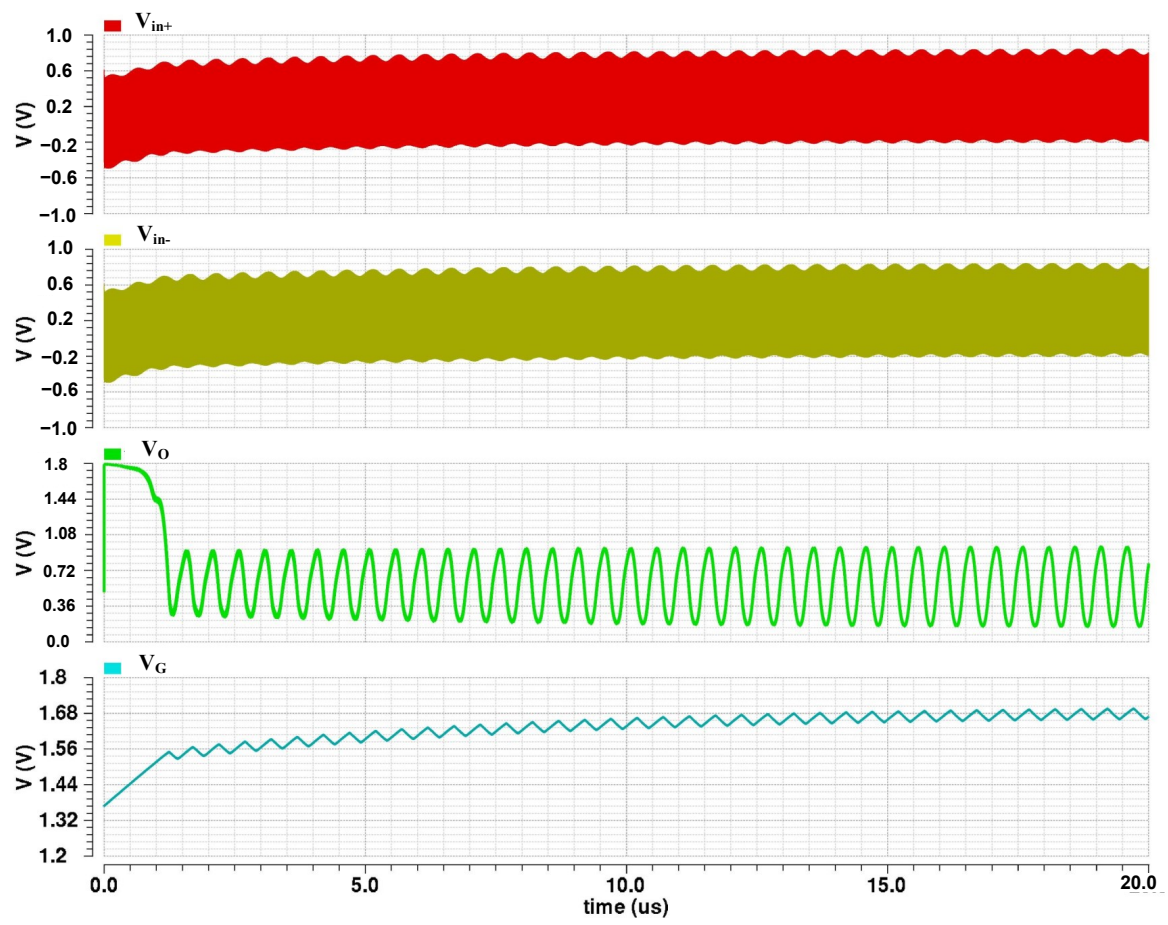

Figure 17. Simulated envelope detector timing waveforms of $V_{i n+}, V_{i n-}, V_{O}$ and $V_{G}$.

Figures 18 and 19 illustrate the output power and PCE of the proposed RF energy harvesting circuits. The proposed envelope detector is the load of RF energy harvesting circuits. The output power reaches $9.28 \mu \mathrm{W}$ with $-17.5 \mathrm{dBm}$ input power. It is enough to power our proposed envelope detector, and this is equivalent to PCE of $52.1 \%$. In order to extract the maximum power, as the input power increases, the corresponding load resistor $R_{L}$ is connected in parallel with $C_{L}$. The value of load resistors $R_{L}$ is labeled in Figure 18 . The highest PCE reaches $55.2 \%$, with $-12.5 \mathrm{dBm}$ input power and $150 \mathrm{~K} \Omega$ load resistors.

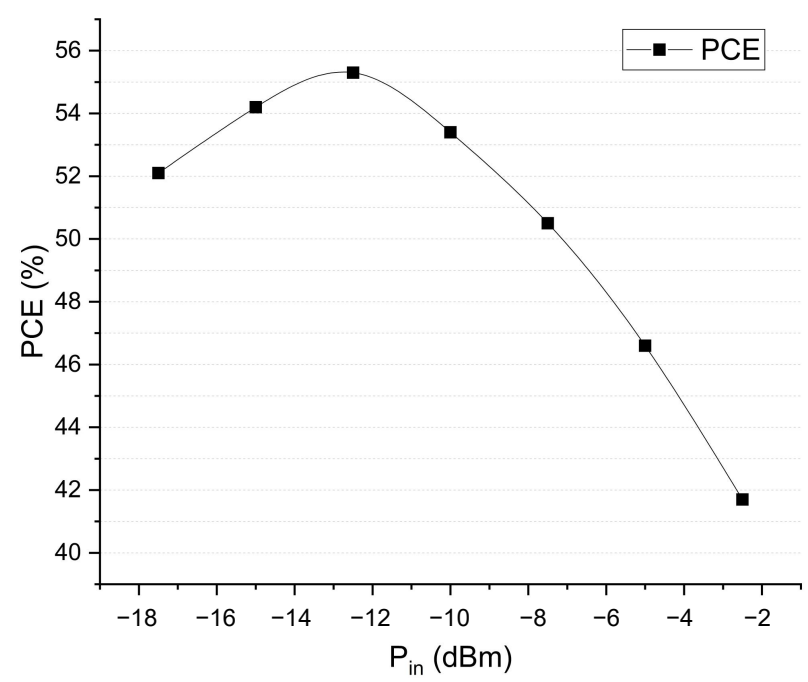

Figure 18. PCE of proposed RF energy harvesting circuits. 


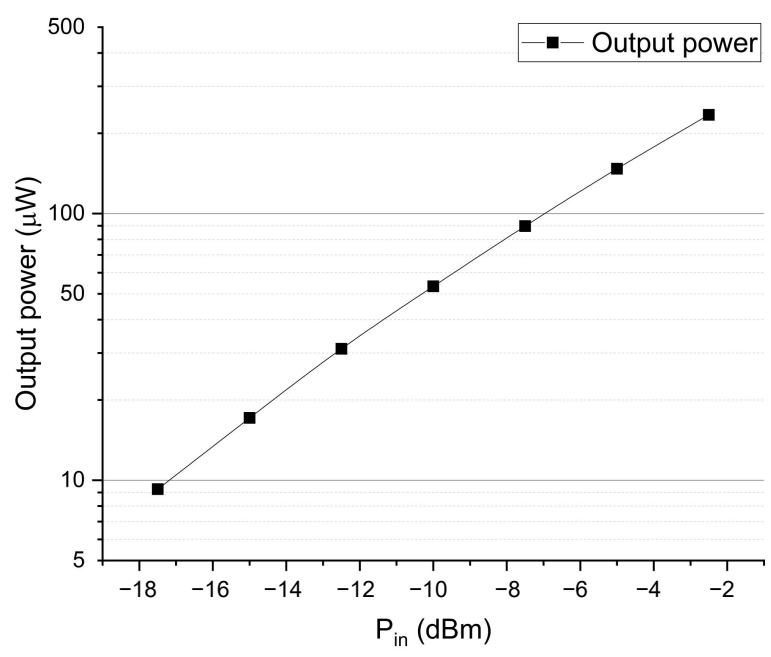

Figure 19. Output power of proposed RF energy harvesting circuits.

Figure 20 illustrates the time waveforms of the DC-DC boost converter. The simulation is performed with $100 \mathrm{~K} \Omega$ load resistor and $-10 \mathrm{dBm}$ input power. The start up circuit is enabled after $0.8 \mathrm{~ms}$ when the output voltage of $\mathrm{RF}$ rectifier $V_{\text {rec }}$ reaches $0.5 \mathrm{~V}$. Once the output voltage of DC-DC boost converter $V_{\text {out }}$ is beyond $1 \mathrm{~V}$, the DC-DC boost converter works in DCM. Therefore, it maintains $V_{\text {rec }}$ near to $V_{\text {rec,opt }}$. As $V_{\text {out }}$ increases to $1.8 \mathrm{~V}$, the control circuits will disable the DC-DC boost converter shortly for over voltage protection. Thus, $V_{\text {out }}$ is clamped at $1.8 \mathrm{~V}$.

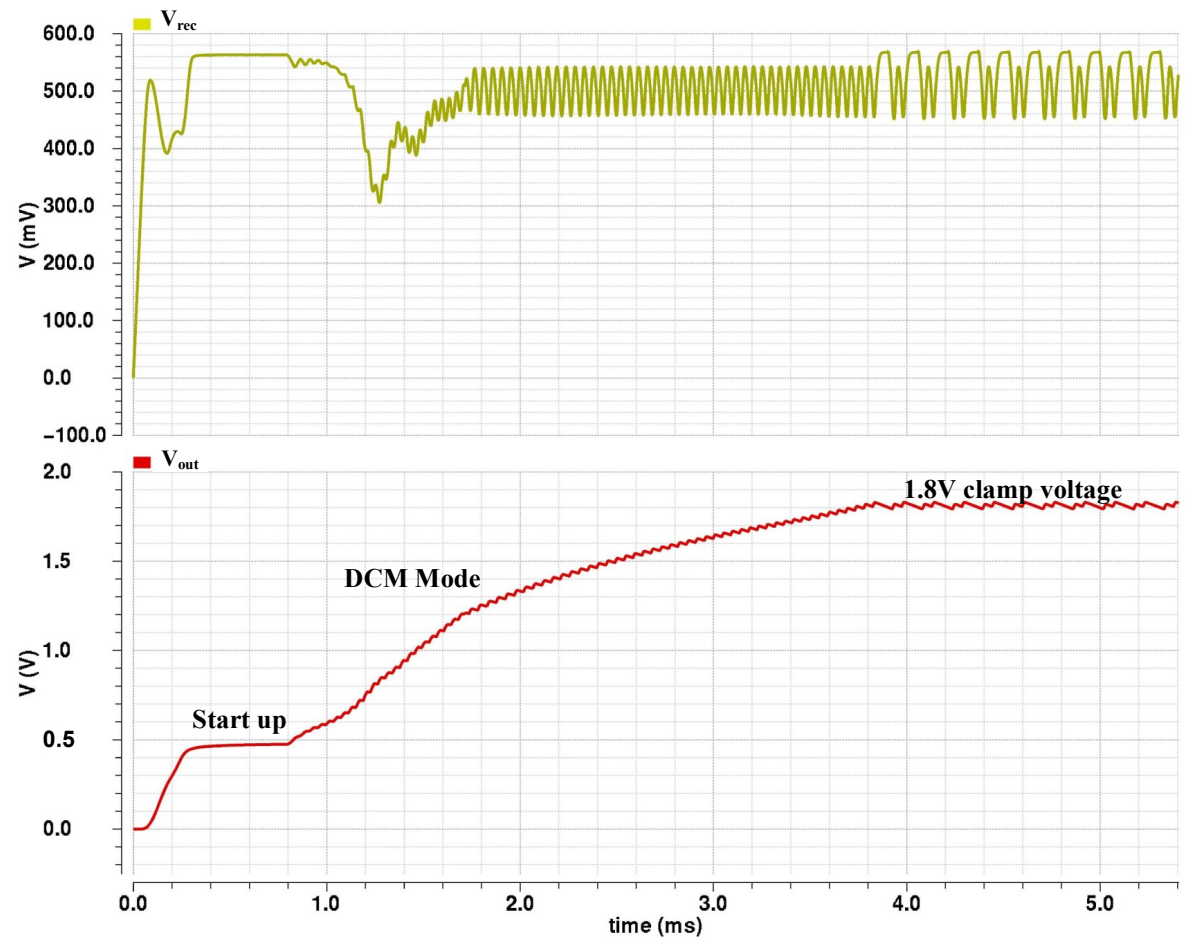

Figure 20. Simulated timing waveforms of DC-DC boost converter.

Table 3 summarizes and compares the performances of the proposed batteryless envelope detector with previously published reports. Our proposed envelope detector achieves $0.25-1 \mathrm{~V}$ input range and $20.37 \mathrm{~dB}$ conversion gain through the adaptive biasing technique, which are improved as compared to previous works. In addition, RF energy 
harvesting circuits have 55.2\% peak PCE and they eliminate the requirement of battery. Therefore, it is a good candidate for SWIPT in WSN applications.

Table 3. Performances comparison of the proposed envelope detector.

\begin{tabular}{cccccc}
\hline Parameters & This Work & [14] & [15] & [16] & [17] \\
\hline CMOS $(\mathrm{nm})$ & 180 & 90 & 180 & 180 & 180 \\
Freq. $(\mathrm{MHz})$ & 915 & 915 & 915 & 13.56 & 920 \\
Power $(\mu \mathrm{W})$ & 9 & 4.8 & 0.219 & 30 & 0.88 \\
Modulation index & $5 \%$ & $60 \%$ & 1 & $2.33 \%$ & 1 \\
Supply voltage $(\mathrm{V})$ & 1.8 & 0.9 & 0.95 & 1.8 & 0.8 \\
Input range $(\mathrm{V})$ & $0.25-1$ & $\mathrm{NA}$ & $\mathrm{NA}$ & $\mathrm{NA}$ & $0.18-0.3$ \\
Data rate $(\mathrm{Mbps})$ & 2 & 2 & 0.04 & 1 & 0.2 \\
Conversion gain $(\mathrm{dB})$ & $20.37 @ 0.5 \mathrm{~V}$ & $-3.5 @ 0.6 \mathrm{~V}$ & $4.4 @ 0.3 \mathrm{~V}$ & $12 @ 1 \mathrm{~V}$ & 8 \\
PCE $(\%)$ & $55.2 @ 31 \mu \mathrm{W}$ & $\mathrm{NA}$ & $\mathrm{NA}$ & $\mathrm{NA}$ & $46.5 @ 1 \mu \mathrm{W}$ \\
\hline
\end{tabular}

\section{Conclusions}

We have proposed a novel batteryless envelope detector with RF energy harvesting. The adaptive biasing technique is introduced to dynamically generate the biasing voltage through the feedback loop in order to obtain a stable conversion gain. Theoretical analysis have been proved that, through the adaptive biasing technique, the proposed envelope detector can achieve both high conversion gain and wide input range. The RF rectifier and DC-DC boost converter with MPPT are also presented. The simulation results indicate that the proposed envelope detector achieves maximum $20.37 \mathrm{~dB}$ conversion gain with $915 \mathrm{MHz}$ carrier frequency and 0.05 modulation index, and it maintains over $14 \mathrm{~dB}$ when the amplitude of input signal is between $0.25 \mathrm{~V}$ and $1 \mathrm{~V}$. When compared to previous works, both input range and conversion gain have been improved. The overall power consumption of the envelope detector is only $9 \mu \mathrm{W}$, and it can be powered by RF energy harvesting circuits, which makes it suitable for SWIPT applications.

Author Contributions: Conceptualization, Y.L. (Yan Li) and X.L.; methodology, Y.L. (Yan Li), Q.S., Z.W. and S.Z.; software, Y.L. (Yan Li) and X.W.; formal analysis, Y.L. (Yan Li) and X.L.; writingoriginal draft preparation, Y.L. (Yan Li); writing-review and editing, X.L. and Q.S.; supervision, Y.L. (Yu Liu). All authors have read and agreed to the published version of the manuscript.

Funding: This research was funded by National Key R\&D Program of China under grant number 2019YFB2204900, 2019YFB2204500, 2018YFC2001103.

Conflicts of Interest: The authors declare no conflict of interest.

\section{References}

1. Bi, S.; Ho, C. K.; Zhang, R. Wireless powered communication: Opportunities and challenges. IEEE Commun. Mag. 2015, 53, 117-125. [CrossRef]

2. Xu, L. D.; He, W.; Li, S. Internet of Things in Industries: A Survey. IEEE Trans. Ind. Informatics 2014, 4, 2233-2243. [CrossRef]

3. Nguyen, C.V.; Nguyen, M.T.; Quyen, T.V.; Le, A.M.; Masaracchia, A.; Nguyen, H.T.; Nguyen, H.P.; Nguyen, L.D.; Nguyen, H.T.; Nguyen, V.Q. Hybrid Solar-RF Energy Harvesting Systems for Electric Operated Wheelchairs. Electronics 2020, 9, 752. [CrossRef]

4. Li, Y.; Li, Q.; Liu, X.; Wang, X.; Liu, Y. A high efficiency CMOS RF rectifier for RF energy harvesting with dynamic self-body-biasing technique. IEICE Electron. Express 2019, 20, 20190462. [CrossRef]

5. Li, Y.; Liu, Y; Liu, X.; Wang, X.; Li, Q. An energy extraction enhanced interface circuit for piezoelectric and thermoelectric energy harvesting. IEICE Electron. Express 2019, 6, 20190066. [CrossRef]

6. Corti, F.; Reatti, A.; Piccirilli, M. C.; Grasso, F.; Paolucci, L.; Kazimierczuk, M. K. Simultaneous Wireless Power and Data Transfer: Overview and Application to Electric Vehicles. In Proceedings of the IEEE International Symposium on Circuits and Systems, Sevilla, Spain, 10-21 October 2020; pp. 1-5.

7. Cong, P.; Chaimanonart, N.; Ko, W. H.; Young, D. J. A Wireless and Batteryless 10-Bit Implantable Blood Pressure Sensing Microsystem With Adaptive RF Powering for Real-Time Laboratory Mice Monitoring. IEEE J. Solid State Circuits 2009, 44, 3631-3644. [CrossRef] 
8. Sutardja, C.; Rabaey, J. M. Isolator-Less Near-Field RFID Reader for Sub-Cranial Powering/Data Link of Millimeter-Sized Implants. IEEE J. Solid State Circuits 2018, 53, 2032-2042. [CrossRef]

9. Daly, D. C; Chandrakasan, A. P. An Energy-Efficient OOK Transceiver for Wireless Sensor Networks. IEEE J. Solid State Circuits 2007, 42, 1003-1011. [CrossRef]

10. Razavi, B. RF Microelectronics, 2nd ed.; Pearson Education: Boston, MA, USA, 2011; pp. 117-118.

11. Ye, D.; Wang, Y.; Xiang, Y.; Lyu, L.; Min, H.; Shi, C. R. A Wireless Power and Data Transfer Receiver Achieving 75.4\% Effective Power Conversion Efficiency and Supporting 0.1\% Modulation Depth for ASK Demodulation. IEEE J. Solid-State Circuits 2020 , 55, 1386-1400. [CrossRef]

12. Nilsson, E.; Svensson, C. Envelope detector sensitivity and blocking characteristics. In Proceedings of the 20th European Conference on Circuit Theory and Design (ECCTD), Linkoping, Sweden, 29-31 August 2011; pp. 773-776.

13. Mousavi, N.; Sharifkhani, M.; Jalali, M. Ultra-low power current mode all-MOS ASK demodulator for radio frequency identification applications. IET Circuits Devices Syst. 2016, 10, 130-134. [CrossRef]

14. Moradi, A.; Zgaren, M.; Sawan, M. A 0.084 nJ/b FSK transmitter and $4.8 \mu$ W OOK receiver for ISM-band medical sensor networks. In Proceedings of the 2013 IEEE 11th International New Circuits and Systems Conference (NEWCAS), Paris, France, 16-19 June 2013; pp. 1-4.

15. Zong, H.; Shen, J,; Liu, S.; Jiang, M.; Ban, Q.; Tang, L.; Meng, F.; Wang, X. An ultra low power ASK demodulator for passive UHF RFID tag. In Proceedings of the 2011 9th IEEE International Conference on ASIC, Xiamen, China, 25-28 October 2011; pp. 637-640.

16. Wang, D.; Hu, J.; Wu, J. An HF Passive RFID Tag IC With Low Modulation Index ASK Demodulator. IEEE Trans. Ind. Electron. 2019, 66, 2164-2173. [CrossRef]

17. Han, P.; Zhang, Z.; Xia, Y.; Mei, N. A 920-MHz Dual-Mode Receiver with Energy Harvesting for UHF RFID Tag and IoT. Electronics 2020, 9, 1042. [CrossRef] 